\title{
Süt Sığırlarında Mevsimsel Beslemenin Sütün Karotenoid İçeriğine Etkileri
}

\author{
Hayrettin Çayıroğlu*, Güray Erener, Ahmet Şahin \\ Ahi Evran Üniversitesi Ziraat Fakültesi Zootekni Bölümü, Kırşehir \\ *e-posta: hayrettincayiroglu@ahievran.edu.tr; Tel: +90 (386) 280 4864; Faks: +90 (386) 2804832
}

\begin{abstract}
Özet
Hayvanların yemlerle aldıkları karotenoidler az ya da çok miktarlarda hayvansal ürünlere aktarılmakta olup ürünlere daha sarımsı bir görünüm kazandırmaktadır. Yaz beslemesinde süt ve süt ürünlerinde daha sarımsı renk, yeşil ot beslemesi ve mer'aya dayalı beslenmeyi çağrıştırdığından diğer ürünlere göre tüketiciler arasında daha fazla tercih sebebi olmaktadır. Fakat kış beslemesinde toplam rasyon içerisindeki yeşil kuru ot oranının yetersiz olması, kaba yem ve silaj kalitesindeki muhtemel bozulmalar, sütün karotenoid madde içeriğinin azalmasına neden olmaktadır. Sütün karotenoid madde içeriği, ırk, laktasyon dönemi ve sayısı, hayvan sağlığı, süt verimi ve sütteki yağ miktarı gibi hayvana bağlı faktörler yanında, kaba yemin yapısı, mer'adan yararlanma ve rasyona $\beta$-karoten ve vitamin A desteklemesi gibi beslemeye dayalı faktörler tarafindan etkilenmektedir. Bu derlemede süt ve ürünlerinin karotenoid maddeler içeriği üzerine mevsimsel beslemenin etkileri irdelenmiştir.
\end{abstract}

Anahtar kelimeler: Karotenoidler, süt sığırları, süt ve ürünleri rengi, mevsimsel yemleme

\section{The Effects of Seasonal Feeding on Milk Carotenoid Content in Dairy Cows}

\begin{abstract}
Dietary consumed carotenoids are transferred to animal products becoming yellow colouring. This colouring gives the information that animals are fed on pasture with green forages in summer feeding. The obtained foods are more preferable for consumers, but in winter feeding, inadequate green coloured hay within the total diet, possible deterioration in the quality of forage and silage causes a decrease in the carotenoid content. The carotenoids content of milk depends on breed, lactation period and rank, milk yield, milk fat, forage characteristics, feeding on pasture facilities, and $\beta$-carotene and vitamin A supplementation of diet. In this presentation, the effects of seasonal feeding on carotenoid content of milk and milk products were examined.
\end{abstract}

Key words: Carotenoids, dairy cattle, milk and milk products colour, seasonal feeding

\section{Giriş}

Karotenoid maddeler; bitki, bazı bakteri, alg ve mikroorganizmalar tarafindan sentezlenebilen ancak hayvanlar tarafindan sentezlenemeyen, genel formülü $\mathrm{C}_{40} \mathrm{H}_{56}$ olan, yapılarında çok sayıda çift bağ bulunan pigmentlerdir (Ölteş ve Atlı, 1997; Gökbulut ve Şarer, 2008; Türkcan ve Ökmen, 2012). Hayvan vücudunda birçok fonksiyonu bulunan karotenoidlerin başlıca fonksiyonu A vitamininin ön maddesi olmasıdır. Bunun yanında antioksidan özelliğine sahip olması, hayvanlarda üreme etkinliğini iyileştirmesi, bağ 1 şıklık sistemini güçlendirmesi, mastitis vakalarını azaltması, kansere karşı koruma gibi fonksiyonları da vardır (Ölteş ve Atlı, 1997; Arıkan ve Muğlalı, 1999; Baysal ve Ersus, 1999; McDowell, 2002; Koca, 2006; Kahyaoğlu ve Kıvanç, 2007; Görgülü, 2009). Hayvansal dokulara ancak tüketilen yemler aracılığı ile taşınırlar ve modifiye edilerek depolanırlar (Karakurt ve Aslantaş, 2008). Ürünlerde açık sarıdan koyu kırmızıya kadar varan farklı tonlarda renk oluşumundan sorumludurlar (Noziere ve ark., 2006; Türkcan ve Ökmen, 2012).
Karotenoidler kimyasal yapılarına göre karotenler ve ksantofiller olmak üzere iki grupta incelenebilirler. Karotenlere $\alpha$-karoten, $\beta$ - karoten ve likopen; ksantofillere ise lutein, zeaksantin, kantaksantin ve astaksantin örnek olarak gösterilebilir. Karotenler A vitamini aktivitesi göstermekte olup beslenme açısından en önemlisi $\beta$-karotendir. Birçok gıda maddesi, süt ve tereyağına sarımsı renk veren en önemli ve aktif karotenoid madde $\beta$-karotendir (Koca, 2006; Erge, 2007; Gökbulut ve Şarer, 2008; Karakurt ve Aslantaş, 2008; Aksoy ve ark., 2012).

Sütün karotenoid madde içeriği, ırk, laktasyon dönemi ve sayısı, hayvan sağlığı, süt verimi ve sütteki yă miktarı gibi hayvana bağlı faktörler yanında, kaba yemin yapıs1, mer'adan yararlanma ve rasyona $\beta$ karoten ve vitamin A desteklemesi gibi beslemeye dayalı faktörler tarafından etkilenmektedir. (Calderon ve ark., 2006; Noziere ve ark., 2006; Koca, 2006; Lindqvist, 2012). $\mathrm{Bu}$ bildiride süt ve ürünlerinin karotenoid maddeler içeriği üzerine mevsimsel beslemenin etkileri irdelenmiştir. 
Çizelge 1. Bazı yemlerin $\beta$-karoten içerikleri ( $\mathrm{mg} / \mathrm{kg}$ kuru madde)

\begin{tabular}{lcl}
\hline Yemler & B-Karoten & Kaynak \\
\hline Yonca (yeşil) & 97.5 & Descalzo ve ark., 2012 \\
Çayır üçgülü (yeşil) & 29 & Kalac, 2012 \\
Doğal çayır otu (yeşil) & 63.8 & Kalac, 2012 \\
Karışık kaba yem (yeşil) & $35.6-56.2$ & Kalac, 2012 \\
Yonca (kuru) & 5.5 & Descalzo ve ark., 2012 \\
Yulaf otu (yeşil) & 66.6 & Descalzo ve ark., 2012 \\
Misır silajı & 13.2 & Descalzo ve ark., 2012 \\
Misır silaji & 24 & Kalac, 2012 \\
Çayır silaji & 106 & Kalac, 2012 \\
Soya küspesi (ekspeller) & 0.3 & Descalzo ve ark., 2012 \\
Ayçiçeği küspesi & 0.35 & Descalzo ve ark., 2012 \\
\hline
\end{tabular}

Süt ve Süt Ürünlerinde Karotenoid Maddeler ve Mevsimsel Etkiler

Hayvanlar, tükettikleri yemler aracılı̆̆ıyla aldıkları karotenoidleri az ya da çok miktarlarda süte ve dolayısıyla da süt ürünlerine de aktararak ürünlerin daha sarımsı bir görünüm kazanmasına neden olmaktadır (Noziere ve ark., 2006). Nitekim süt ve süt ürünlerinde sarımsı görünüm, mer'aya dayalı beslenmeyi çağrıştırdığından diğer ürünlere göre tercih sebebi olmaktadır (Noziere ve ark., 2006; Descalzo ve ark., 2012). Ayrıca daha sarımsı bir görünüm özellikle otlatmaya dayalı üretim sistemlerinin bir unsuru olarak oluşmakta ve "temiz ve yeşil imaj veren" bir hayvansal üretim algısı oluşmasına da neden olmaktadır (Calderon ve ark., 2006). Bunun yanında sütteki yüksek karotenoid içeriği, süt ve süt ürünlerinin besleme değerini de iyileştirerek tüketicilerde daha iyi bir imaj oluşmasına ve bu tür ürünlere olan ilginin artmasına sebep olmaktadır (Calderon ve ark., 2006; Noziere ve ark., 2006; Descalzo ve ark., 2012; Kalac, 2012).

Bitkilerin karotenoid içeriği bitkinin türü, olgunluk devresi, iklim, sezon, bitkinin aldığı 1şık şiddeti ve azot miktarı, toprağın yapısı ve uygulanan tarımsal teknikler, kaba yemin cinsi, çeşidi, yapısı, bitki olgunluk dönemi, otlatma sistemi ve yemlere uygulanan işlemler tarafindan etkilenmektedir (Martin ve ark., 2005; Koca, 2006; Noziere ve ark., 2006; Lindqvist, 2012; Aksoy ve ark. 2012; Descalzo, 2012). Baz1 yemlerin $\beta$-karoten içerikleri Çizelge 1'de verilmiştir.

En iyi karoten kaynakları yeşil çayırlar, baklagiller ve diğer yeşil bitkiler (Mogensen ve ark., 2012) olup kurutma işlemi esnasında önemli kayıplar gerçekleşmektedir. Güneşte kurutulan otların karotenoid içeriğinin, özellikle kurutma sırasında meydana gelen yağmurlar nedeniyle, $\% 83$ oranında azaldığı, bu kaybın güneş 1şınlarından kaynaklanabileceği belirtilmektedir (Noziere ve ark., 2006; Lindqvist, 2012). Silajda ise kayıp çok daha az düzeylerde (Ayaşan ve Karakozak, 2010) olup silonun geç kapatılması, silodaki yüksek pH ve silolama süresinin uzaması kayıpları arttırmaktadır. Fakat iyi fermente edilmiş silajlarda kayıp genellikle $\% 20$ 'den daha az olmaktadır (Noziere ve ark., 2006; Lindqvist, 2012).

Genel olarak mevsimler bitkilerin $\beta$-karoten içeriğini önemli ölçüde etkilemekte olup bitkinin olgunluk devresi, ışı̆̆a maruz kalma şiddeti ve mevsim ilerlemesi ile azalmaktadır (Martin ve ark., 2005; Aksoy ve ark. 2012).

Yaz aylarında mer'alardan yararlanan veya yeşil yemlerle beslenen hayvanların süt ve süt yağı, kış aylarında beslenen hayvanların sütlerine göre daha sarı bir görünüme sahip olmaktadır (Martin ve ark., 2005). Bunun başlica nedeni, yemlerin $\beta$-karoten içeriği olup tüketilen yemlerin $\beta$-karoten içeriği ne kadar fazla olursa süt ve süt ürünlerinin $\beta$-karoten içeriği de o kadar fazla olmakta (Martin ve ark., 2005; Calderon ve ark., 2006; Noziere ve ark., 2006; Lindqvist, 2012) dolayısıyla da ürün daha sarıms1 bir görünüm kazanmaktadır (Hurşit ve Akgün, 2008; Aksoy ve ark. 2012; Lindqvist, 2012). Özellikle, bahar sütü ile yapılan peynirler kış sütü ile yapılanlardan, ot silajı yedirilerek elde edilen sütler ile kışın yapılan peynirler, özellikle uzun süre yerde kurutulmuş kuru ot sütlerinden yapılan peynirlere göre çok daha sarımsı bir renk almaktadır. Mısır silajı ise çok daha az karoten içerdiğinden bunların sütleri genellikle beyaz peynir yapımında kullanılmaktadır (Coulon ve ark. 2004).

Süt sığırlarının kış yemlemesinde hayvanlar genellikle yaz aylarında hasat edilerek depolanan ve azalmış $\beta$ karoten içeriğine sahip yemlerle beslendiklerinden bu 
hayvanların sütleri de daha beyaz bir görünüme sahip olmaktadır. Nitekim Toledo ve Andrén (2003) tarafından yapılan araştırmada, ahırda yemlemenin son ayı olan Nisan ayında sütün $\beta$-karoten içeriğinin en düşük, Haziran, Kasım ve Şubat aylarında ise en yüksek olduğu bildirilmiştir. Aynı araştırmada, Ağustos ayında sütün $\beta$-karoten içeriğinin daha düşük olmasının nedenleri olarak yüksek sıcaklıklar, düşük yağışlar ve düşük mera kalitesi gösterilmiştir.

Noziere ve ark. (2006)'nın bildirdiğine göre; kaba yemlerin karotenoid içeriği üzerine bitkinin olgunluk devresi ve sezonun etkilerini incelemek üzere Fransa'da yapılan bir çalışmada, Mayıs ve Haziran aylarında mer'adaki bitkilerin karotenoid içeriği çok fazla etkilenmemiş (620-700 mg/kg KM), Ağustos başında ise bir miktar düşmüştür (430 $\mathrm{mg} / \mathrm{kg} \mathrm{KM})$. Yine Noziere ve ark. (2006)'nın bildirdiğine göre; Yeni Zelanda'da yapılan bir çalışmada, otlatma mevsimi boyunca çayırların karotenoid konsantrasyonunda çok fazla değişim olmamıştır. Bu durum kaba yemlerin karotenoid içeriğinin, yemin elde edildiği ülkenin mevsimsel özellikleri ile değişebileceğini ortaya koymaktadir.

Yemlerin karotenoid içerikleri, kaba yemin türü ve çeşidine göre de farklıklar gösterebilmektedir (Noziere ve ark., 2006; Yılmaz, 2010). Yapılan çalışmalar, kılçıksız brom (Bromus inermis) ve kanarya çiminin (Phalaris arundinacea), buğday otuna (Agropyron repens) göre $\% 50$, kırmızı yoncanın da çok yıllık çim veya domuz ayrı̆̆ına göre \%25 daha fazla karoten içeriğine sahip olduğunu göstermiştir (Noziere ve ark., 2006).

Noziere ve ark. (2006)'nın bildirdiğine göre; yapılan bir çalışmada, doğal çayır otuna ilaveten çayır otu silajı ile beslenen hayvanların sütlerinde, doğal çim ve doğal mer'a kuru otu veya kesif yem ve misır silajı içeren rasyonlara göre daha yüksek $\beta$-karoten bulunmuştur.

Yemlere uygulanan kurutma işlemi de yemlerin karotenoid içeriğini etkilemektedir. Dehidrasyon sıcaklığı ve süresi arttıkça kayıp da artmaktadır. Ancak yine de dehidrasyon ile meydana gelen karotenoid kayb1, hem kuru ot hem de silaja göre daha az olmaktadır (Noziere ve ark., 2006).

Süt sığırlarında, çayır silajı yerine ani kuru ot değişikliği, plazma ve sütün her ikisinde de $\beta$ - karoten içeriğinde hızlı bir düşüşe neden olmaktadır. Bunun aksine kuru ot yerine ani çayır silajına geçiş, rasyondaki $\beta$-karotenin miktarına bağlı olarak 2-4 hafta içinde, süt ve plazma $\beta$-karoten renginde hızlı bir artış meydana getirmektedir (Noziere ve ark., 2006).

\section{Sonuç}

Süt sığırlarının mevsimsel beslenmesi, süt ve süt ürünlerinin rengini önemli ölçüde etkilemekte olup özellikle yaz aylarında elde edilen sarımsı renkte ürünler, mer'aya dayalı beslenmeyi veya yeşil ot beslemesini çağrıştırdığından, diğer ürünlere göre tüketiciler arasında daha fazla tercih sebebi olabilmektedir. Bunun aksine kış beslemesinde toplam rasyon içerisindeki yeşil kuru ot oranının yetersiz olmas1, kaba yem ve silaj kalitesindeki muhtemel bozulmalar, sütün karotenoid madde içeriğinin azalmasına neden olmaktadır. Gerek süt ve süt ürünlerinin karotenoid madde içeriği ve gerekse de tüketici tercihleri ve süt tüketim alışkanlığının belirlenmesi konusunda detaylı çalışmalar yapılması, süt sığırcılığı sektörünün gelişmesinde önemli katkılar sağlayacaktır.

\section{Kaynaklar}

Aksoy, A., Macit, M., Karaoğlu, M. 2012. Hayvan besleme. Atatürk Üniversitesi Ziraat Fakültesi Ders Yayınları No: 220. Erzurum.

Arıkan, Ş., Muğlalı Ö. H. 1999. Bazı çiftlik hayvanlarının üreme fonksiyonları üzerine $\beta$ karotenin etkisi. Lalahan Hay. Arast. Enst. Derg. 39(2): 85-94.

Ayaşan, T. ve Karakozak, E. 2010. Hayvan beslemede $\beta$-karoten kullanılması ve etkileri. Kafkas Üniversitesi Veteriner Fakültesi Dergisi 16(4): 697705.

Baysal, T. ve Ersus, S. 1999. Karotenoidler ve insan sağlığı. Gida 24(3): 17-185.

Coulon, J. B., Delacroix-Buchet, A., Martin, B., Pirisi, A. 2004. Relationships between ruminant management and sensory characteristics of cheeses: A review. Lait 84: 221-241.

Calderon, F., Tornambe, G., Martin,B., Paradel, P., Chauaveau-Duriot, B., Noziere, P. 2006. Effects of mountain grassland maturity stage and grazing management on carotenoids in sward and cow's milk. Anim. Res. 55: 533-544.

Descalzo, A. M., Rossetti, L., Páez, R., Grigioni, G., García, P.T., Costabel, L., Negri, L., Antonacci, L., Salado, E., Bretschneider, G., Gagliostro, G., Comerón, E., Taverna, M.A. 2012. Differential characteristics of milk produced in grazing systems and their impact on dairy products. http://cdn.intechopen.com/pdfs/39316/InTechDifferential_characteristics_of_milk_produced_in_g razing_systems_and_their_impact_on_dairy_produc ts.pdf Chapter 15 (Erişim tarihi: 19.03.2014). 
Erge, H.S. 2007. Domateste (Lycopersicum esculentum) karotenoid madde dağılımı ve antioksidant aktivite. Ankara Üniversitesi Fen Bilimleri Enstitüsü. Doktora Tezi. http://agris.fao.org/agrissearch/search.do?recordID=TR2012000727 (Erişim tarihi:11.03.2014).

Gökbulut A. ve Şarer, E. 2008. Karotenoitler ve sağlık. Ankara Ecz. Fak. Derg. 37(3): 235-256.

Görgülü, M. 2009. Büyük ve küçükbaş hayvan besleme. Çukurova Üniversitesi Ziraat Fakültesi Genel Yayın No: 224; Ders Kitapları Yayın No: A-78.

Hurşit, A. K. ve Akgün, A. 2008. Süt bilimi ve teknolojisi. Ondokuz Mayıs Üniv. Mühendislik Fak. Ders Kitabı. 2. Baskı. Samsun.

Kahyaoğlu, M. ve Kıvanç, M. 2007. Endüstriyel atık maddelerden mikrobiyal yolla beta karoten üretimi. Yüzüncü Yıl Üniversitesi, Ziraat Fakültesi, Tarım Bilimleri Dergisi (J. Agric. Sci.) 17(2): 61-66.

Kalac, P. 2012. Carotenoids, ergosterol and tocopherols in fresh and preserved herbage and their transfer to bovine milk fat and adipose tissues: A review. J Agrobiol 29(1): 1-13.

Karakurt, H. ve Aslantaş, R. 2008. Bitki renk maddelerinin (pigmentler) oluşum ve değişim fizyolojisi. Alatarım 7(2): 34-41.

Koca, N. 2006. Havuçlarda (Daucus carota L.) karotenoidler ve antioksidan aktivite. Ankara Üniversitesi Fen Bilimleri Enstitüsü, Gıda Mühendisliği Anabilim Dalı Doktora Tezi.

Lindqvist, H. 2012. $\alpha$-Tocopherol and $\beta$-carotene in forages and their utilisation by dairy cows in organic production. Swedish University of Agricultural Sciences, Faculty of Veterinary Medicine and Animal Science, Department of Animal Environment and Health, Skara. Doctoral Thesis.
Martin, B., Verdier-Metz, I., Buchin, S., Hurtaud, C., Coulon, J. B. 2005. How do the nature of forages and pasture diversity influence the sensory quality of dairy livestock products? Anim. Sci. 81(2):205-212. http://journals.cambridge.org/action/displayAbstract ?fromPage $=$ online $\&$ aid $=777396 \&$ fileId $=$ S13577298 0500072X (Erişim tarihi:11.03.2014).

McDowell, L. R. 2002. Recent advances in minerals and vitamins on nutrition of lactating cows. Pakistan Journal of Nutrition 1(1): 8-19.

Mogensen, L., Kristensen, T., Søegaard, K., Jensen, S. K., Sehested, J. 2012. Alfa-tocopherol and betacarotene in roughages and milk in organic dairy herds. Livestock Science 145: 44-54.

Noziere, P, Graulet, B., Lucas, A., Martin, B., Grolier, P., Doreau. M. 2006. Carotenoids for ruminants: From forages to dairy products. Anim. Feed. Sci. Tech. 131: 418-450.

Ölteş, S. ve Atlı, Y. 1997. Karotenoidlerin insan sağlı̆̆ açısından önemi. Pamukkale Üniversitesi Mühendislik Fakültesi Mühendislik Bilimleri Dergisi 3(1): 249-254.

Toledo, P. ve Andrén, A. 2003. Content of B-carotene in organic milk. Food, Agriculture \& Environment Vol.1(2):122-125. http://www.worldfood.net/download/journals/2003-issue 2/j2-food113.pdf (Erişim tarihi: 25.03.2014).

Türkcan, O. ve Ökmen, G. 2012. Mikrobiyal karotenoidler. Türk Bilimsel Derlemeler Dergisi 5(1): 115-122.

Yılmaz, İ. 2010. Karotenoidler. İnönü Üniversitesi Tıp Fakültesi Dergisi 17(3): 223-231. 